\title{
The Evaluation of Protein C Activity and Some Inflammatory Markers in Synovia of Patients Undergoing Total Knee Arthroplasty
}

\author{
Ahmet Ata Alturfan¹, Remzi Tözün², Nesrin Emekli³ \\ ${ }^{1}$ Department of Medical Laboratory, Cerrahpaşa School of Medicine, Health Services Vocational, istanbul, Turkey \\ ${ }^{2}$ Department of Orthopedics and Traumatology, Faculty of Medicine, İstanbul University, İstanbul, Turkey \\ ${ }^{3}$ Department of Biochemistry, Faculty of Dentistry, Marmara University, İstanbul, Turkey
}

\begin{abstract}
Objective: Total knee arthroplasty (TKA) is a major risk factor for thrombosis in patients over 40 years of age and this risk persists for several weeks after the surgery. Since inflammatory mechanisms affect coagulation and the natural anticoagulant system, we aimed to investigate protein $C$ activities and inflammatory markers in patients undergoing TKA surgery.

Material and Methods: We included 20 osteoarthritis patients and 20 healthy controls. Protein C activity and tumor necrosis factor- $\alpha$ (TNF- $\alpha$ ) levels in plasma and synovia were evaluated by ELISA technique.

Results: In the patient group, protein C activities decreased and TNF- $\alpha$ levels increased significantly both in synovia and plasma when compared with the controls. Erythrocyte sedimentation rate of the patient group was found to be significantly elevated in comparison to the controls. On the other hand, serum $C$ reactive protein values increased insignificantly when compared to controls.
\end{abstract}

Conclusion: The decreased activity of protein C and increased levels of inflammatory markers in preoperative plasma and synovia of the patient group may enhance the risk for developing thrombosis.

Key Words: Protein C, hypercoagulability, inflammation, knee arthroplasty

Received: 19.10.2009 Accepted: 22.02.2010

\section{Introduction}

Osteoarthritis (OA) is a group of chronic and painful conditions affecting synovial joints (1) and is commonly described as a non-inflammatory disease in order to distinguish it from inflammatory arthritis. However, occasionally, inflammation is recognized as contributing to the symptoms and progression of primary osteoarthritis (POA) (2).

Total knee arthroplasty (TKA) surgery is a major risk factor for thrombosis in patients over 40 years of age and this risk persists for several weeks after the surgery. Hypercoagulability is a feature of both inflammatory and degenerative joint diseases, which may or may not contribute to postoperative thrombosis. The causes of the hypercoagulability in chronic arthritis have not been completely identified (3).

Due to hypercoagulability (3) and fibrin formation in cartilage in patients suffering OA (4), natural anticoagulants are predominantly important to disease progression (5). The natural anticoagulants function to dampen the elevation of cytokine levels. Hence, down regulation of anticoagulant pathways not only promotes thrombosis but also amplifies the inflammatory process (6). In inflammatory conditions, tumor necrosis factor- $\alpha$ (TNF- $\alpha$ ) has been implicated in a number of pathophysiological processes. Chondrocytes obtained from patients with OA actively produce TNF- $\alpha$ (7) and TNF- $\alpha$ elic- its the expression of tissue factor (TF), the main precursor of protein $C(P C)$ on blood cells (8).

In the literature, it has been reported that patients undergoing TKA surgery have a tendency to thrombosis and there is an extravascular fibrin formation in joint spaces, the reasons for which are open to discussion $(3,9,10)$. In our current study, we wanted to clarify and confirm the relationship between PC activity and inflammation by evaluating CRP, ESR and TNF- $\alpha$ levels in preoperative plasma and synovia of POA patients to determine the risk or susceptibility for development of thrombosis during TKA or even a few days after TKA surgery.

\section{Patients and Methods}

Twenty female patients with a median age of 59 years (range 48-80) undergoing TKA surgery were included in the study. The control group was formed by 20 volunteer healthy females with a median age of 54 years (range 44-68). Informed consent was obtained from all patients according to the Declaration of Helsinki. Diagnosis of the patients were made on the clinical examination, pains after activity, swellings, rushes, joint movement examinations, knee pain and osteophytes on radiographs and radiographic examinations (11). The patient group comprised of individuals who had end-stage OA of the knee (determined by their surgeon and confirmed by X-ray) 
and who were scheduled for TKA surgery. Patients with diabetes, cancer, heart or liver disorder were not included in the study. While samples were being taken from the patients, they were asked if they received any medication. All participants were asked to stop non-steroidal anti-inflammatory medications (NSAID) for a period of 3 days prior to testing.

To obtain plasma, blood was collected from the patient group and controls in the morning after an overnight fast. Samples were centrifuged at $1500 \mathrm{~g}$ for 10 minutes at $4^{\circ} \mathrm{C}$. To obtain serum, venous blood samples were collected and then centrifuged at $1500 \mathrm{~g}$ for 10 minutes at $4^{\circ} \mathrm{C}$. Synovia was centrifuged at $1000 \mathrm{rpm}$ for $10 \mathrm{~min}$ to sediment cells. The protocol for obtaining synovia from knee joints was approved by the institutional ethics review board and joint aspiration was performed only when medically necessary. Our control group consisted of patients with a torn meniscus of a 1 month history, without inflammation in their knee joint (12). Control specimens were obtained from patients immediately before arthroscopy for trauma to menisci. During aspiration of synovia, none of the patients had swollen joints or a raised sedimentation rate and elevated CRP. All specimens were stored at $-80^{\circ} \mathrm{C}$. The samples taken were subjected to PC, TNF- $\alpha$ CRP and ESR tests.

\section{Determination of Protein C Activity:}

The STA-Stachrom PC (Lot No: 5096C01) kit was used for the quantitative determination of the functional PC level by the synthetic chromogenic substrate method. PC is activated by the specific activator. The quantity of enzyme thus formed is measured by its amidasic activity on the synthetic chromogenic substrate. The intensity of the color produced is directly proportional to the level of PC initially present in the synovia and plasma of patients and the control group. PC assay of the samples to be tested is automatically carried out by the STA at $405 \mathrm{~nm}$ as soon as the samples have been loaded.

\section{Determination of TNF- $\alpha$ Levels:}

Measurement of TNF- $\alpha$ in plasma and synovia of the TKA and control samples (total amount of free TNF- $\alpha$ plus the amount of TNF- $\alpha$ bount to soluble receptors) have been employed for quantitative sandwich enzyme immunoassay technique (Lot No. 062805-Biosource Elisa kit).

\section{Determination of Routine Laboratory Tests:}

Quantitative CRP measurement was carried out using hs CRP nephelometric method (BN II Nephelometer Dade Behring, Marburg) and ESR was determined by the method of Gambino et al. (13).

\section{Statistical Analysis}

Student -t test was used for statistical evaluation when the two groups were compared. Value of $p<0.05$ was considered significant. The statistical software package SPSS 11.0 (SPSS, Inc., Chicago, III., USA) was used.

\section{Results}

A significant decrease was observed in PC levels both in synovia and in plasma of POA patients when compared to controls. ( $p=0.0002$ and $p=0.0051$ respectively) (Table 1$)$. In addition, in the patient group, a statistically significant increase was observed in TNF- $\alpha$ levels both in synovia and in plasma ( $p=0.02$ and $p=0.049$ respectively) (Table 1 ).

Seventeen of the 20 patients with preoperative ESR had an ESR $>15 \mathrm{~mm} /$ hour and 3 patients had preoperative ESR of $<15$. Sixteen of the 20 patients with a preoperative CRP had a $C R P>10 \mathrm{mg} / \mathrm{L}$ and 4 patients had a CRP $<5$. Moreover, ESR levels of the patient group was found to be very significant in comparison to the control group $(p=0.003)$. On the other hand, serum CRP levels were increased insignificantly when compared to controls $(p=0.079)$ (Table 2$)$.

\section{Discussion}

Since TKA surgery is a major risk factor for thrombosis and hypercoagulability is a feature of both inflammatory and degenerative joint diseases, although the causes have not completely been identified, we aimed to evaluate PC activity and inflammatory indicators such as TNF- $\alpha$, ESR and CRP in patients undergoing TKA surgery. Herein, PC activity indicating hypercoagulation significantly decreased in the patient group.

TKA is one method for treating advanced stage osteoarthritis, or chronic wear of knee joint cartilage (14). However, infection can develop as a complication after TKA surgery (15). In knee arthroplasty surgery, the damaged bone and cartilage are replaced with metal and plastic surfaces that are shaped to restore knee movement and function (14). In this patient group, exercise is severely hampered by stress such as surgical trauma and ischemic reperfusion injury, which can induce inflammatory reactions and release numerous inflammatory mediators (16).

Trauma is accompanied by changes in blood levels of cytokines. Cytokines are inflammatory mediators responsible for numerous clinical conditions in patients undergoing knee arthroplasty surgery (17). Inflammatory cytokines, especially TNF- $\alpha$, can down-regulate thrombomodulin and endothelial

Table 1. Plasma and synovia PC activity and TNF- $\alpha$ levels of patients with POA undergoing knee arthroplasty

\begin{tabular}{|c|c|c|c|c|}
\hline & \multicolumn{2}{|c|}{ Plasma } & \multicolumn{2}{|c|}{ Synovia } \\
\hline & $\begin{array}{c}\text { POA } \\
(n=20)\end{array}$ & $\begin{array}{l}\text { Control } \\
(n=20)\end{array}$ & $\begin{array}{c}\text { POA } \\
(n=20)\end{array}$ & $\begin{array}{l}\text { Control } \\
(n=20)\end{array}$ \\
\hline $\begin{array}{l}\text { Protein } \\
\text { C (\%) }\end{array}$ & \multicolumn{2}{|c|}{$\begin{array}{c}80.90 \pm 14.17110 .60 \pm 20.16 \\
p=0.0051\end{array}$} & \multicolumn{2}{|c|}{$\begin{array}{c}12.10 \pm 1.6648 .00 \pm 6.72 \\
p=0.0002\end{array}$} \\
\hline $\begin{array}{l}\text { TNF- } \alpha \\
(\mathrm{pg} / \mathrm{ml})\end{array}$ & \multicolumn{2}{|c|}{$\begin{array}{c}19.13 \pm 6.30 \quad 13.49 \pm 4.43 \\
p=0.049\end{array}$} & \multicolumn{2}{|c|}{$\begin{array}{c}27.37 \pm 9.722 .94 \pm 1.08 \\
p=0.02\end{array}$} \\
\hline
\end{tabular}

Table 2. Serum CRP and ESR levels of patients with POA undergoing knee arthroplasty

\begin{tabular}{|c|c|c|}
\hline & $\operatorname{POA}(n=20)$ & Control $(n=20)$ \\
\hline \multirow[t]{2}{*}{ CRP (mg/L) } & $11.50 \pm 8.81$ & $3.10 \pm 1.37$ \\
\hline & \multicolumn{2}{|c|}{$p=0.079$} \\
\hline \multirow[t]{2}{*}{$\mathrm{ESR}(\mathrm{mm} / \mathrm{h})$} & $31.70 \pm 20.15$ & $7.80 \pm 2.35$ \\
\hline & \multicolumn{2}{|c|}{$p=0.003$} \\
\hline
\end{tabular}


protein $\mathrm{C}$ receptor, rendering the endothelium less capable of activating $\mathrm{PC}$, more sensitive to thrombin activation, and more likely to produce proinflammatory mediators (18).

In OA, TNF- $\alpha$ also appears to be an important mediator of matrix degradation and a pivotal cytokine in inducing synovial membrane inflammation. An enhanced expression of TNF- $\alpha$ receptor has also been reported in chondrocytes and synovial cells of OA (19). Bottner et al. (20) evaluated the role of TNF- $\alpha$ in 78 patients undergoing TKR surgery and found significantly higher levels of TNF- $\alpha$ in the peripheral blood when compared with the control group. Similarly, in the present study we also found elevated TNF- $\alpha$ levels in synovia and plasma in the patient group compared with the control group. TNF- $\alpha$ is secreted by monocytes transforming into macrophages. This increase could be a consequence of mainly local activation of TNF production (21). Other investigators support our findings $(17,22)$.

In the present study, both CRP and TNF- $\alpha$ were elevated in the patient group. Inflammation increases CRP concentrations (8) and TNF- $\alpha$ was found to be influential in CRP synthesis in blood (23). Overproduction of TNF- $\alpha$ may induce systemic response from the liver, the main source of CRP in our patient group. It also leads to complement activation and thereby increases the available procoagulant membrane surface. Complement activation brought on by inflammatory reactions can thus contribute to a hypercoagulable state by providing the key membrane surfaces on which the initiation and amplification aspects of coagulation can proceed (24). While ESR is a non-specific test depending on the plasma viscosity, it generally increases in such inflammatory responses as CRP (25). In the present study the increase in ESR together with TNF- $\alpha$ and CRP, were taken as primary osteoarthritis inflammation indicators.

Inflammation may initiate clotting and decrease the activity of natural anticoagulant mechanisms (24). Decreased PC activity in the presurgical POA patients may be the result of inflammation-induced activation of coagulation since extravascular coagulation has been reported to be accelerated in synovia $(4,26)$. Decreased PC activity may reflect the general state of activation in the inflamed joint as well. In contrast to decreased PC activity, increased TNF- $\alpha$ both in plasma and synovia, together with increased ESR and increased CRP support our argument. Legendre et al. (27) compared activated PC levels of OA and RA synovia in order to examine the relation between activated PC and metalloproteinases. In contrast to our findings they stated that PC was specifically activated in RA patients.

In this study, the reason for the dramatic decrease in PC activity might be the elastase released from neutrophils. Eckle I et al. (28) reported that PC activity was reduced by elastase. Neutrophil elastase is known to be released from neutrophils during blood coagulation and inflammation and acts as a mediator of tissue damage, including endothelial cell injury, which can lead to organ failure (29).

To our knowledge, this is the only study in the literature evaluating PC activity in synovia in patients undergoing TKA surgery. In the patient group, the decreased PC activity in synovia was much more enhanced than that in the plasma. Although there is no specific information about the source of PC in synovia, it may be the leak from plasma through the synovial membrane, or PC may be synthesized locally by the synovium cells or fibroblasts. Our interpretation is not valid when it is considered that PC leaks from blood to synovial. However the reason for the passage of $\mathrm{PC}$ into synovia from blood may be to prevent extravascular fibrin formation in the synovia or it may represent a more specific activation of the PC pathway in the patient group.

Consequently, we observed increased inflammation and an associated tendency to in-vivo coagulation in the patient group. Our results could be evidence of an impaired PC anticoagulant pathway and the role of inflammation in exacerbating this process. Decreased activity of PC can be proposed as an "early marker" to determine a higher risk or susceptibility for development of thrombosis before TKA surgery or even a few days after operation.

\section{Acknowledgements}

We thank Dr. Ebru Emekli Alturfan for her assistance with the manuscript.

\section{Conflict of Interest}

No conflict of interest was declared by the authors.

\section{References}

1. Haris ED, Budd RC, Firestein GS, Genovese MC, Sergent JS, Ruddy S. et al. Pathogenesis of osteoarthritis. In: Cesare PE, Abramson SB, editors. Kelley's Textbook of Rheumatology, 7th ed. Philadelphia: Elsevier; 2005;1493-8.

2. Benito MJ, Veale DJ, FitzGerald O, van den Berg WB, Bresnihan B. Synovial tissue inflammation in early and late osteoarthritis. Ann Rheum Dis 2005;64:1263-7.

3. Craven S, Dewar L, Yang X, Ginsberg J, Ofosu F. Altered regulation of in-vivo coagulation in orthopedic patients prior to knee or hip replacement surgery. Blood Coagul Fibrinolysis 2007;18:219-25.

4. Weinberg JB, Pippen AM, Greenberg SC. Extravascular fibrin formation and dissolution in synovial tissue of patients with osteoarthritis and rheumatoid arthritis. Arthritis and Rheumatism 1991;34:996-1005.

5. Fisher CR, Yan SB. Protein C levels as a prognostic indicator of outcome in sepsis and related disease. Crit Care Med 2000;28:S49-56.

6. Cicala C, Cirino G. Linkage between inflammation and coagulation: an update on the molecular basis of the crosstalk. Life Science 1998;62:1817-24.

7. Van de Loo FA, Joosten LAB, van Lent P, Arntz OJ, van den Berg WB. Role of interleukin -1 tumor necrosis factor alfa and interleukin-6 in cartilage proteoglycan metabolism and destruction: effect of in situ blocking in murine antigen and zymosan induced arthritis. Arthritis Rheum 1995;38:164-72.

8. Cermak J, Key NS, Bech R, Balla J, Cacob HS, Vercellotti GM. C reactive protein induces human peripheral blood monocytes to synthesize tissue factor. Blood 1993;82:513-20.

9. Cheras PA, Whitaker AN, Blackwell EA, Sinton TJ, Chapman MD, Peacock KA. Hypercoagulability and hypofibrinolysis in primary osteoarthritis. Clin Orthop 1997;334:57-67.

10. So AK, Varisco PA, Kemkes-Matthes B, Kerkenne-Morad C, Chobaz-Peclat V. Arthritis is linked to local and systemic activation of coagulation and fibrinolysis pathways. J Thromb Haemost 2003;1:2510-5.

11. Altman R, Asch E, Bloch D, Bole G, Borenstein D, Brandt K, et al. Development of criteria for the classification and reporting of 
osteoarthritis. Classification of osteoarthritis of the knee. Arthritis Rheum 1986;29:1039-49.

12. Marklund SL, Bjelle A, Elmqvist LG. Elmqvist. 1986. Superoxide dismutase isoenzymes of the synovial fluid in rheumatoid arthritis and in reactive arthritides. Ann. Rheum. Dis. 1986;45:847-51.

13. Gambino SR, Dire JJ, Monteleon M, Budd DC. The Westergren sedimentation rate using K3 EDTA. Tech Bull Regist Med Technol 1965;35:1-8.

14. Feng $Y$, Ju $H$, Yang $B$, An $H$. Effects of a selective cyclooxygenase-2 inhibitor on postoperative inflammatory reaction and pain after total knee replacement. J Pain 2008;9:45-52.

15. Atay T, Baydar ML, Heybeli N, Kırdemir V. Total Artroplasti Uygulanan Dizde Brusella Protez Enfeksiyonu: Artroskopi ve Medikal Tedavi ile Protezi Korunan Bir Olgu Sunumu. Trakya Üniv Tıp Fak Derg 2008;25:252-5.

16. Andersson I, Tylman M, Bengtson JP, Bengtsson A. Complement split products and pro-inflammatory cytokines in salvaged blood after hip and knee arthroplasty. Can J Anaesth 2001;48:251-5.

17. Bottner F, Wegner A, Winkelmann W, Becker K, Erren M, Götze C. Interleukin-6, procalcitonin and TNF-alpha: markers of periprosthetic infection following total joint replacement. J Bone Joint Surg Br 2007;89:94-9.

18. Esmon CT. Protein $C$ anticoagulant pathway and its role in controlling microvascular thrombosis and inflammation. Crit Care Med 2001;29:S48-51.

19. Amin AR. Regulation of tumor necrosis factor alpha and tumor necrosis factor converting enzyme in human osteoarthritis. Osteoarthritis Cartilage 1999;7:392-4.

20. Bottner F, Sheth N, Chimento GF, Sculco TP. Cytokine levels after transfusion of washed wound drainage in total knee arthroplasty: a randomized trial comparing autologous blood and washed wound drainage. J Knee Surg 2003;16:93-7.

21. Olsnes C, Stavang H, Olofsson J, Aarstad HJ. TNF-alpha is secreted by monocytes in transit to become macrophages, but not by peripheral blood monocytes, following OK-432 (lyophilized S. pyogenes) stimulation. Scand J Immunol 2007;66:684-93.

22. Cameron-Donaldson M, Holland C, Hungerford DS, Frondoza CG. Cartilage debris increases the expression of chondrodestructive tumor necrosis factor-alpha by articular chondrocytes. Arthroscopy 2004;20:1040-3.

23. Westacott $\mathrm{Cl}$, Atkins RM, Dieppe PA, Elson CJ. Tumour necrosis factor-alpha receptor expresion on chondrocytes isolated from human articular cartilage. J Rheumatol 1994;21:1710-5.

24. Esmon CT. The interactions between inflammation and coagulation. Br J Haematol 2005;131:417-30.

25. Sturmer T, Brenner H, Koenig W, Gunther KP. Severity and extent of osteoarthritis and low grade systemic inflammation as assessed by high sensitivity $C$ reactive protein. Ann Rheum Dis 2004;63:200-5.

26. Nakano S, Ikata T, Kinoshita I, Kanematsu J, Yasuoka S. Characteristics of the protease activity in synovia from patients with rheumatoid arthritis and osteoarthritis. Clin Exp Rheumatology 1999;17:161-70.

27. Legendre NB, Smith S, March L, Jackson C. Elevation of activated protein $C$ in synovial joints in rheumatoid arthritis and its correlation with matrix metalloproteinase 2. Arthritis Rheumatism 2005;50:2151-6.

28. Eckle I, Seitz R, Egbring R, Kolb G, Havemann K. Protein C degradation in vitro by neutrophil elastase. Biol Chem Hoppe Seyler 1991;372:1007-13.

29. Katsumata S, Nagashima M, Kato K, Tachihara A, Wauke K, Saito $S$, et al. Changes in coagulation-fibrinolysis marker and neutrophil elastase following the use of tourniquet during total knee arthroplasty and the influence of neutrophil elastase on thromboembolism. Acta Anaesthesiologica Scandinavica 2005;49:510-6. 